\title{
Efficacy of an insecticide paint against insecticide- susceptible and resistant mosquitoes - Part 1: Laboratory evaluation
}

\author{
Beatriz Mosqueira ${ }^{1 *}$, Stéphane Duchon², Fabrice Chandre², Jean-Marc Hougard², Pierre Carnevale², \\ Santiago Mas-Coma ${ }^{1}$
}

\begin{abstract}
Background: The main malaria vector Anopheles gambiae and the urban pest nuisance Culex quinquefasciatus are increasingly resistant to pyrethroids in many African countries. There is a need for new products and strategies. Insecticide paint Inesfly 5A IGR ${ }^{\mathrm{TM}}$, containing two organophosphates (OPs), chlorpyrifos and diazinon, and insect growth regulator (IGR), pyriproxyfen, was tested under laboratory conditions for 12 months following WHOPES Phase I procedures.

Methods: Mosquitoes used were laboratory strains of $C x$. quinquefasciatus susceptible and resistant to OPs. The paint was applied at two different doses $\left(1 \mathrm{~kg} / 6 \mathrm{~m}^{2}\right.$ and $\left.1 \mathrm{~kg} / 12 \mathrm{~m}^{2}\right)$ on different commonly used surfaces: porous (cement and stucco) and non-porous (softwood and hard plastic). Insecticide efficacy was studied in terms of delayed mortality using 30-minute WHO bioassay cones. IGR efficacy on fecundity, fertility and larval development was studied on OP-resistant females exposed for 30 minutes to cement treated and control surfaces.

Results: After treatment, delayed mortality was high (87-100\%) even against OP-resistant females on all surfaces except cement treated at $1 \mathrm{~kg} / 12 \mathrm{~m}^{2}$. Remarkably, one year after treatment delayed mortality was $93-100 \%$ against OP-resistant females on non-porous surfaces at both doses. On cement, death rates were low 12 months after treatment regardless of the dose and the resistance status. Fecundity, fertility and adult emergence were reduced after treatment even at the lower dose $\left(p<10^{-3}\right)$. A reduction in fecundity was still observed nine months after treatment at both doses $\left(p<10^{-3}\right)$ and adult emergence was reduced the higher dose $\left(p<10^{-3}\right)$.

Conclusions: High mortality rates were observed against laboratory strains of the pest mosquito $C x$. quinquefasciatus susceptible and resistant to insecticides. Long-term killing remained equally important on nonporous surfaces regardless the resistance status for over 12 months. The paint's effect on fecundity, fertility and adult emergence may continue to provide an additional angle of attack in reducing overall population densities when the lethal effect of OPs diminishes over time. Some options on how to deal with porous materials are given. Implications in vector control are discussed.
\end{abstract}

\section{Background}

Every year, 300-500 million clinical episodes of malaria occur, resulting in about one million deaths [1]. A vast majority of these deaths involve children less than 5 years old in sub-Saharan Africa [2,3]. The fighting of malaria in sub-Saharan Africa is mainly focused on

\footnotetext{
* Correspondence: bmosqueira@yahoo.com

'Departamento de Parasitología, Facultad de Farmacia, Universidad de Valencia, Av. Vicent Andrés Estellés s/n, 46100 Burjassot, Valencia, Spain Full list of author information is available at the end of the article
}

vector control through the use of insecticide-treated nets (ITNs) and indoor residual insecticide spraying (IRS) $[4,5]$. At present, pyrethroids are the only insecticides recommended for treatment of mosquito nets [6]. Despite the great value of pyrethroid-treated nets in malaria vector control, their efficacy may be threatened by resistance of major malaria vectors to this class of insecticides [7]. IRS is the main method of attacking adult mosquitoes in houses, but the technique requires

\section{C) Biomed Central}

(c) 2010 Mosqueira et al; licensee BioMed Central Ltd. This is an Open Access article distributed under the terms of the Creative Commons Attribution License (http://creativecommons.org/licenses/by/2.0), which permits unrestricted use, distribution, and reproduction in any medium, provided the original work is properly cited. 
teams of trained personnel and special equipment to be transported to where they are needed [8].

A present recommendation towards resistance management is alternating or using in combination different insecticides or novel strategies in the framework of an integrated vector management [9] while respecting the Stockholm Convention on Persistent Organic Pollutants (POPs) of finding sustainable alternatives to POPs in integrated pest management practices where possible [10].

Insecticide paint Inesfly $5 \mathrm{~A} \mathrm{IGR}^{\mathrm{m}}$ is composed of two organophosphates (OPs), chlorpyriphos (1.5\%) and diazinon $(1.5 \%)$ and an insect growth regulator (IGR), pyriproxyfen $(0,063 \%)$. The product is a white vinyl paint with an aqueous base. Active ingredients reside within $\mathrm{Ca} \mathrm{CO}^{3}+$ resin microcapsules. The formulation allows a gradual release of active ingredients, increasing its durability. Microcapsules range from one to several hundred micrometers in size. Toxicology studies performed so far support the paint's safety in terms of irritancy (ocular, dermal and systemic), cytotoxicity and mutagenicity [11] and allergenicity [12]. Acute inhalation toxicity studies classified this paint as Category III (according to WHO) and category IV (according to EPA) - no warning label required in either case [12]. Analysis on cholinesterase levels showed no variations before/after treatment. Values were within reference values for all subjects [13].

The efficacy of Inesfly 5A IGR ${ }^{\text {im }}$ was studied under laboratory conditions for over 12 months at the Laboratoire de Lutte contre les Insectes Nuisibles/Institut de Recherche pour le Développement (LIN/IRD), the WHO reference laboratory for insecticide testing, in Montpellier, France. These highly-controlled evaluations against mosquitoes specifically resistant to the paint's insecticides were triggered by the encouraging results obtained during preliminary testing in malaria-endemic areas in Benin and Côte d'Ivoire, West Africa, against local populations of Anopheles gambiae the main malaria vector in sub-Saharan Africa. Resistance to OPs has been described in vector and pest mosquitoes in various parts of the world, including West Africa [14,15]. The paint's efficacy was tested against laboratory strains of the urban pest Culex quinquefasciatus susceptible and resistant to OPs. At the time of the study, there was no laboratory strain of An. gambiae specifically resistant to OPs. Efficacy was studied in two ways: delayed mortality and effect of the IGR on fecundity, fertility and larval development.

\section{Methods}

\section{Delayed mortality}

30 minute-WHO bioassay cones [16] were performed against two laboratory strains of $C x$. quinquefasciatus: Cx. quinquefasciatus S-Lab is an insecticide susceptible reference strain [17]. Culex.quinquefasciatus SR is homozygote for the ace- $1^{R}$ resistant gene involved in the resistance to OPs and carbamates, but has the same genetic background as S-Lab [18]. Unfed, 3-5 day old females bred at the LIN insectarium were placed in forced contact with four different surfaces: softwood and hard plastic (non-porous materials) and ready-mixed cement and ready-mixed stucco (porous materials). There were two treated and two controls for each kind of surface. Treated surfaces were painted at two doses, 1 $\mathrm{kg} / 6 \mathrm{~m}^{2}$ (manufacturer's recommended dose to leave surfaces completely white) and $1 \mathrm{~kg} / 12 \mathrm{~m}^{2}$. For each kind of surface, one control was left untreated and the other one was painted at $1 \mathrm{~kg} / 6 \mathrm{~m}^{2}$ with the same paint but without the insecticides and the IGR. Paint was applied undiluted with a regular brush and left to dry for 48 hours. After a 30-minute exposure, mosquitoes were introduced in 150-ml plastic cups provided with honey-juice. Tests were done in four repeats using 15 females per cone. Females were left at a temperature of $27 \pm 1^{\circ} \mathrm{C}$ and a relative humidity of $80 \%$, for 24 -hour delayed mortality assessments. Tests were done at intervals of six months for one year. When not tested, surfaces were stored in aluminium foil at a temperature of $27 \pm 1^{\circ} \mathrm{C}$ and a relative humidity of $80 \%$. Delayed mortality was analysed using Epi-Info 6 . Where values were $<5$, Fisher exact tests were used. Because bioassay tests are subject to variations, a $99 \%$ confidence interval was applied.

IGR efficacy on fecundity, fertility and larval development Females were 4-5 day-old to increase the probability of having had females fertilised by male mosquitoes. LINreared $C x$. quinquefasciatus OP-resistant females were exposed to treated and control surfaces for 30 minutes. Females alive 24 hours after a 30-minute exposition, were put in cages and allowed to blood-feed for one night. Females that had been well blood-fed were put in a new cage and given honey-juice every two days. At T0, 50 blood fed females were tested per surface. At T9, 30 blood-fed females were tested per surface. At T0 and T9, blood feeding took place about 36 hours after previous exposition to treated or control surfaces. Efficacy was measured in terms of fecundity (number of eggs laid), fertility (\% hatching) and larval development (\% pupation and \% emergence). Tests were not done using susceptible $C x$. quinquefasciatus S-Lab, because they all died during the 30-minute exposition. Tests were carried out on the most porous surface, cement, because not enough females survived exposition to other surfaces. Eggs were counted with a dissecting microscope and placed in plastic measuring containers with $2 \mathrm{~L}$ of water for hatching. Water loss due to evaporation was replaced daily. Larvae were fed every two days. 
The mean number of eggs was compared between treated and non-treated surfaces using a student $\mathrm{T}$ test. Differences in \% hatching, \% pupation, and \% emergence were analysed using Epi-Info 6 . Where values were $<5$, Fisher exact tests were used.

\section{Results}

\section{Delayed mortality}

Delayed 24-hour mortality at T0 was $98-100 \%$ (compared to control, $\mathrm{p}<10^{-3}$ ) for both, susceptible S-Lab and OP-resistant $C x$. quinquefasciatus on non-porous surfaces and porous surfaces treated at $1 \mathrm{~kg} / 6 \mathrm{~m}^{2}$. While non-porous surfaces performed equally well regardless the dose and the resistance status, porous surfaces, cement and stucco, treated at the lower dose 1 $\mathrm{kg} / 12 \mathrm{~m}^{2}$ performed less optimally against OP-resistant mosquitoes yielding mortalities of $87 \%\left(\mathrm{p}<10^{-3}\right)$ and $15 \%\left(\mathrm{p}<10^{-2}\right)$ respectively. Efficacy had dropped by six months on cement surfaces treated at both doses on resistant and susceptible mosquitoes while, on stucco, only OP-resistant $C x$. quinquefasciatus experienced a drop. Mortality at 24 hours was of $90-100 \%$ (compared to control, $\mathrm{p}<10^{-3}$ ) 12 months after treatment even against resistant mosquitoes at the lower dose on all but porous surfaces (Table 1).

IGR efficacy on fecundity, fertility and larval development A significant reduction in the number of eggs laid was shown at 0 and 9 months after treatment at either dose $\left(\mathrm{p}<10^{-3}\right)$ (Tables 2 and 3$)$. A reduction in egg hatching was observed at T0 $\left(\mathrm{p}<10^{-3}\right)$, but not at T9. An increased mortality from the nymph to the adult stage was shown 0 months after treatment at the lower dose $\left(\mathrm{p}<10^{-3}\right)$, and 9 months after treatment only at the higher dose $\left(\mathrm{p}<10^{-3}\right)$ No differences were found on the duration of the larval development cycle. No IGR effect was observed 12 months after treatment.

\section{Discussion}

After treatment with insecticide paint Inesfly $5 \mathrm{~A} \mathrm{IGR}^{\mathrm{m}}$, $100 \%$ of OP-susceptible females died after 24-hours on all surfaces, porous and non-porous at both doses, $1 \mathrm{~kg} /$ $6 \mathrm{~m}^{2}$ and $1 \mathrm{~kg} / 12 \mathrm{~m}^{2}$. Killing was significant $(87-100 \%)$ even against OP-resistant females on all surfaces except cement treated at the lower dose, $1 \mathrm{~kg} / 12 \mathrm{~m}^{2}$.

One year after initial treatment, mortality rates were still quite high, 93-100\%, on non-porous surfaces (softwood and hard plastic) at both doses and against both, OP-resistant and susceptible females. On the other hand, the lethal effect on porous surfaces like cement had disappeared by six months after treatment against resistant and susceptible mosquitoes.

Long-term efficacy was an issue of porosity of materials rather than the $\mathrm{pH}$ of materials or the dose applied: active principles are kept in an acid $\mathrm{pH}$ within its microcapsule, making it more resistant to alkalinity than other conventional paints. To study whether efficacy hinged more on porosity than dose, a parallel study was performed. Cement-made surfaces painted with a control layer and an insecticide paint layer at $1 \mathrm{~kg} / 6 \mathrm{~m}^{2}$, performed as well as two insecticide paint layers at $1 \mathrm{~kg} / 6$ $\mathrm{m}^{2}$, even though the latter had twice the dose (Mosqueira et al., unpublished data). Hence, the first layer acted as a screen (even if it did not have insecticide) that allowed the bioavailability of the insecticide on the second layer. Porosity is also an issue for IRS. DDT may last for six months on cement surfaces, though it usually leaves walls stained [19].

A Phase II field study on this same paint, Inesfly 5A $\mathrm{IGR}^{\mathrm{TM}}$, was performed in Benin, West Africa for one year against local An. gambiae and Cx. quinquefasciatus populations resistant to pyrethroids. Experimental houses were built with locally-made cement. Long-term efficacy tests included 30 minute-WHO bioassay cones using the insecticide susceptible reference strain $C x$.

Table 1 Delayed 24-hour mortality rates of susceptible Cx. quinquefasciatus S-Lab and OP-resistant Cx. quinquefasciatus after a 30-minute exposure to control and Inesfly(r) treated surfaces using WHO bioassay cones.

\begin{tabular}{|c|c|c|c|c|c|c|c|c|c|c|}
\hline \multirow[t]{2}{*}{$\begin{array}{l}\text { Culex \% Delayed } \\
\text { mortality } 24 \mathrm{~h} \\
(\mathrm{~N}=60)\end{array}$} & \multirow[t]{2}{*}{$\begin{array}{l}\text { Control } 1 \\
\text { No paint }\end{array}$} & \multirow[t]{2}{*}{$\begin{array}{c}\text { Control } 2 \\
\text { Control } \\
\text { Paint }\end{array}$} & $\begin{array}{c}\text { Cement } \\
1 \mathrm{Kg} / 6 \\
\mathrm{~m} 2\end{array}$ & $\begin{array}{c}\text { Cement } \\
1 \mathrm{Kg} / 12 \\
\mathrm{~m} 2\end{array}$ & $\begin{array}{c}\text { Stucco } \\
1 \mathrm{Kg} / 6 \\
\mathrm{~m} 2\end{array}$ & $\begin{array}{c}\text { Stucco } \\
1 \mathrm{Kg} / 12 \\
\mathrm{~m} 2\end{array}$ & $\begin{array}{l}\text { Softwood } \\
1 \mathrm{Kg} / 6 \mathrm{~m} 2\end{array}$ & $\begin{array}{l}\text { Softwood } 1 \\
\mathrm{Kg} / 12 \mathrm{~m} 2\end{array}$ & $\begin{array}{c}\text { Plastic } \\
1 \mathrm{Kg} / 6 \\
\mathrm{~m} 2\end{array}$ & $\begin{array}{c}\text { Plastic } \\
1 \mathrm{Kg} / 12 \\
\mathrm{~m} 2\end{array}$ \\
\hline & & & \multicolumn{4}{|c|}{ Porous Surfaces } & \multicolumn{4}{|c|}{ Non-Porous Surfaces } \\
\hline T0 OP-Susceptible & 0.5 & 0.4 & $100+$ & $100+$ & $100+$ & $100+$ & $100+$ & $100+$ & $100+$ & $100+$ \\
\hline T0 OP-Resistant & 2 & 2.2 & $100+$ & $15.7+$ & $100+$ & $87.3+$ & $100+$ & $100+$ & $100+$ & $100 \dagger$ \\
\hline T6 OP-Susceptible & 2.2 & 2.9 & 3.1 & 1.7 & $100+$ & $96.7+$ & $100+$ & $100+$ & $100+$ & $100+$ \\
\hline T6 OP-Resistant & 1.6 & 3.3 & 0 & 0 & $31.7 \dagger$ & 3.3 & $100+$ & $100+$ & $100+$ & $100+$ \\
\hline T12 OP-Susceptible & 0 & 2.1 & 2 & 0 & $91.4 \dagger$ & $20.3+$ & $100+$ & $100+$ & $100+$ & $100+$ \\
\hline T12 OP-Resistant & 1.5 & 1 & 4.1 & 5.3 & $20.3 t$ & 5.3 & $100+$ & $93.2+$ & $100+$ & $100+$ \\
\hline
\end{tabular}

Control 1 = No paint; Control $2=$ Paint without insecticide at $1 \mathrm{Kg} / 6 \mathrm{~m}^{2}$. Culex $=C x$. quinquefasciatus; T0 $=0$ months after treatment, T6 $=6 \mathrm{months}$ after treatment, $\mathrm{T} 12=12$ months after treatment, $\mathrm{N}=$ sample size per surface tested; $(-)$ females had already died during the first hour. $\dagger=$ significant differences from control $(P<0.05)$. 
Table 2 IGR effect on fecundity, fertility and larval development of females exposed to treated surfaces for 30 minutes

\begin{tabular}{lcccc}
\hline To - Cement $(\mathbf{N}=\mathbf{5 0})$ OP-resistant Culex & Egg number & \% Egg-hatching & \% Pupation & \% Emergence \\
\hline C1/NO Paint & 2104 & 51.8 & 39.6 & 79.5 \\
\hline C2/Paint NO insecticide & 2473 & 48.8 & 40.0 & \\
\hline Insecticide at $1 \mathrm{Kg} / 6 \mathrm{~m}^{2}$ & & \multicolumn{4}{c}{ No survivors } \\
\hline Insecticide at $1 \mathrm{Kg} / 12 \mathrm{~m}^{2}$ & $800 \dagger$ & $41.3 \dagger$ & 45.5 & $52.7 \dagger$
\end{tabular}

Control $1=$ No paint; Control $2=$ Paint without insecticide at $1 \mathrm{Kg} / 6 \mathrm{~m}^{2} ;$ Culex $=C x$. quinquefasciatus; T0 $=0$ months after treatment; $\mathrm{N}=$ sample size per surface tested. $\dagger=$ significant differences from control $(P<0.05)$.

quinquefasciatus S-Lab. Six months after treatment, mortality rates in the Phase II study on cement-made surfaces treated with one layer at $1 \mathrm{Kg} / 6 \mathrm{~m}^{2}$ were still very high, $98-100 \%$ [20] compared to the $3 \%$ observed in the Phase I study. The difference observed in the long-term efficacy may be due to the type of cement used in Phase I and II, ready-mixed cement versus traditionally made cement, respectively. The greater the proportion of water to cement, the more porous the hardened cement will be. To test this hypothesis, Phase I surfaces with locally made cement were made in Benin. Surfaces were kept away from light when not tested. Temperature and humidity were the same to Phase II experimental houses. Mortality rates were lower on the Phase I Benin surfaces but differences were not significant compared to Phase II cement houses (Mosqueira et al., unpublished data) as opposed to the mortality rates obtained on Phase I mixed-cement surfaces.

Another recent study has tested the efficacy and the residual effect of Inesfly $5 \mathrm{~A} \mathrm{IGR}^{\mathrm{mw}}$ insecticide paint against the main vector of Chagas disease in South America, Triatoma infestans, on different surfaces (wood, cement block and adobe bricks). Insecticide paint yielded longer and higher mortality rates in triatomines than other conventional products [21], and porosity also seemed to be an issue - cement surfaces performed worse than wood and even adobe-made surfaces. Insecticide paints have been used for some time concomitantly with home improvement as a control method for Chagas disease with good results [22,23].

Pyriproxyfen is toxic to a broad spectrum of insects during their developmental stages. Research on the dengue vector, Aedes aegypti, shows that contaminated adults can render oviposition sites unproductive by horizontal dissemination of pyriproxyfen even at small concentrations [24-26]. A study performed by Itoh et al [24] showed pyriproxyfen had a larger impact on fecundity when females were exposed to pyriproxyfen before blood feeding. Inversely, pyriproxyfen's effect on egg-hatching $[24,27,28]$ and adult emergence $[24,28]$ seems to be higher when females have blood fed before being exposed to treatment.

In the present study, the effect of pyriproxyfen was studied on OP-resistant $C x$ quinquefasciatus females that survived a 30-minute exposition to cement-treated surfaces. Cement surfaces were chosen because, being the most porous, they were the only ones that left enough females alive to follow their offspring. Females were exposed to treated surfaces about 36 hours before blood feeding, a timing that would favour a reduction in fecundity over fertility and adult emergence. This is in fact the observation made. For the first nine months, a reduction in fecundity was observed at both doses. A reduction in adult emergence was observed also for nine months but only at the higher dose. An effect on fertility was only observed after treatment and not after nine months. In a recent Phase I evaluation on adult Anopheles stephensi females exposed to pyriproxyfen $2 \%$ one day after blood feeding, results were the opposite. A reduction in fertility in treatment groups compared to control, whereas fecundity was also reduced but differences failed to be significant [29]. The potential application of horizontal dissemination in malaria vector control needs to be studied [30]. Could the pyriproxyfen that was picked up by females that have survived a

Table 3 IGR effect on fecundity, fertility and larval development of females exposed to treated surfaces for 30 minutes

\begin{tabular}{lcccc}
\hline T9 - Cement $(\mathbf{N}=\mathbf{3 0})$ OP-resistant Culex & Egg number & \% Egg-hatching & \% Pupation & \% Emergence \\
\hline C1/NO Paint & 1908 & 75.8 & 56.3 & 87.8 \\
\hline C2/Paint NO Insecticide & 2002 & 73.1 & 60.0 & 84.4 \\
\hline Insecticide at $1 \mathrm{Kg} / 6 \mathrm{~m}^{2}$ & $1216 \dagger$ & 77.5 & 64.6 & $65.9+$ \\
\hline Insecticide at $1 \mathrm{Kg} / 12 \mathrm{~m}^{2}$ & $1156+$ & 70.9 & 59.9 & 86.6 \\
\hline
\end{tabular}

Control 1 = No paint; Control $2=$ Paint without insecticide at $1 \mathrm{Kg} / 6 \mathrm{~m}^{2} ;$ Culex $=C x$. quinquefasciatus; $\mathrm{T} 9=9$ months after treatment; $\mathrm{N}=$ sample size per surface tested. $\dagger=$ significant differences from control $(P<0.05)$ 
prolonged contact with painted walls be then transferred to the oviposition sites of malaria vectors? A project is in progress on different surfaces and blood feeding timing.

Results on non-porous surfaces are satisfying. There is a need to look for ways to deal with the porosity of surfaces like cement. Possible options may include two layers of paint, as discussed above, applying a coating resin, or even natural oil sealers first. The way surfaces are made also makes a difference: cement surfaces can be made less porous depending on the proportion of substances used. Hardwood is more porous than softwood. What would seem clear is that solutions need to be "user-friendly" and appealing in keeping with one of the paint's operational advantages.

There may be a reason to be optimistic about the potential that the insecticide paint may have as an additional tool in malaria and pest control: 1) High longterm killing rates against OP-resistant mosquitoes, 2) IGR's effect on fecundity, fertility and adult emergence and, 3) operational advantages: users can apply the paint themselves and take responsibility for their home improvement.

\section{Conclusions}

Laboratory assays against OP-resistant $C x$. quinquefasciatus point at the paint's potential in attaining high mortality rates for up to 12 months despite resistance status. Ways to deal with the porosity of certain materials need to be explored. Pyriproxyfen's effect on the fecundity, fertility and adult emergence of exposed adult females affords an added tool in reducing overall pest and malaria vector population densities when the lethal effect of OPs diminishes over time. The paint is easily applied and improves communities' homes. A semi-field study performed following WHOPES Phase II procedures in Benin, West Africa against local populations of pyrethroid-resistant An. gambiae and Cx. quinquefasciatus populations has confirmed the product's promising profile. Future goals include performing a large-scale entomological, epidemiological and community acceptability study in West Africa.

\footnotetext{
Acknowledgements

This study was funded by Project Number 07-CAP3-1513 of the Agencia Española de Cooperación Internacional para el Desarrollo (AECID), Ministry of Foreign Affaires, Madrid, Spain, and by the Red de Investigación de Centros de Enfermedades Tropicales (RICET), Project Number RD06/0021/0017 "Redes Temáticas de Investigación Cooperativa", Fondo de Investigación Sanitaria (FIS), Ministry of Health, Madrid, Spain. We thank the University of Valencia and the IRD for their support, particularly Luc Finot for his help on some of the evaluations. We thank Dr. Thierry Baldet for his advice on the manuscript.
}

\section{Author details}

${ }^{1}$ Departamento de Parasitología, Facultad de Farmacia, Universidad de Valencia, Av. Vicent Andrés Estellés s/n, 46100 Burjassot, Valencia, Spain.
UR016, Institut de Recherche pour le Développement (IRD), BP 64501, 34394 Montpellier Cedex 5, France.

\section{Authors' contributions}

PC and SMC conceived the protocol. PC, SMC, SD and BM designed the study. SD, FC and JMH critically contributed to the implementation of the study. BM conducted evaluations. The manuscript has been drafted by BM and has been revised by SMC and SD. All authors read and approved the final manuscript.

\section{Competing interests}

The authors declare that they have no competing interests.

Received: 1 October 2010 Accepted: 25 November 2010 Published: 25 November 2010

\section{References}

1. WHO: The world malaria report 2005. World Health Organization Geneva; 2005 [http://rbm.who.int/wmr2005/].

2. Breman JG, Egan A, Keusch GT: The intolerable burden of malaria: a new look at numbers. Am J Trop Med Hyg 2001, 64(1-2):iv-vii.

3. Snow RW, Craig MH, Newton C, Steketee RW: The public health burden of Plasmodium falciparum malaria in Africa: deriving the numbers. Disease Control Priorities Project Working Paper No 11. Fogarty International Center, National Institutes of Health Bethesda, Maryland; 2003.

4. Lengeler C, Sharp B: Indoor residual spraying and insecticide-treated nets. In: Reducing malaria's burden: evidence of effectiveness for decision makers. Global Health Council Washington D.C; 2003, 17-24.

5. Lengeler $C$ : Insecticide-treated bed nets and curtains for preventing malaria. Cochrane Database of Syst Rev 2008 [http://www.cochrane.org].

6. Zaim M, Aitio A, Nakashima N: Safety of pyrethroid-treated mosquito nets. Med Vet Entomol 2000, 14:1-5.

7. Baleta A: Insecticide resistance threatens malaria control in Africa. Lancet 2009, 374:1581-1582.

8. Najera JA, Zaim M: Malaria Vector Control. Insecticides for Indoor Residual Spraying. WHO/CDS/WHOPES/2001.3. World Health Organization Geneva; 2001

9. Beier JC, Keating J, Githure Jl, Macdonald MB, Impoinvil DE, Novak RJ: Integrated vector management for malaria control. Malar J 2008, 7(Suppl 1):S4.

10. United Nations Environment Programme: Stockholm Convention on Persistant Organic Pollutants (POPs). UNEP/Convention/The POPs 2010.

11. Spanish Ministry of Health and Consumer Affairs: Report on the study of the toxicity and irritability of Inesfly 5A. Health Institute Carlos III Madrid; 1996.

12. International center of training and medical investigations (CIDEIM): Toxicity studies on Inesfly 5A IGR. CIDEIM, Cali (Colombia); 2003 [http://www. cideim.org.co].

13. National Center of Tropical Diseases (CENETROP), Santa Cruz de la Sierra (Bolivia). 2004 [http://www.cenetrop.org.bo].

14. Chandre F, Darriet F, Doannio JMC, Riviere F, Pasteur N, Guillet P: Distribution of organophosphate and carbamate resistance in Culex pipiens quinquefasciatus (Diptera: Culicidae) from West Africa. J Med Entomol 1997, 34:664-671.

15. N'Guessan R, Darriet F, Guillet P, Carnevale P, Lamizana MT, Corbel V, Koffi AA, Chandre F: Resistance to carbosulfan in field populations of Anopheles gambiae from Côte d'Ivoire based on reduced sensitivity of acetylcholinesterase. Med Vet Entomol 2003, 17:19-25.

16. WHO: Test Procedures for insecticide resistance monitoring in malaria vectors, bio-efficacy and persistence of insecticides on treated surfaces. Report of the WHO Informal Consultation. Document WHO/CDS/CPC/ MAL/1998.12. World Health Organization Geneva; 1998, 1-43.

17. Georghiou GP, Metcalf RL, Gidden FE: Carbamate-resistance in mosquitoes: selection of Culex pipiens fatigans Wied (= Culex quinquefasciatus) for resistance to Baygon. Bull World Health Organ 1966, 35:691-708.

18. Berticat C, Boquien G, Raymond M, Chevillon C: Insecticide resistance genes induce a mating competition cost in Culex pipiens mosquitoes. Genetics Research 2002, 79:41-47. 
19. Najera JA, Zaim M: Malaria Vector Control. Insecticides for Indoor Residual Spraying. (WHO/CDS/WHOPES/2001.3). World Health Organization Geneva; 2001.

20. Mosqueira B, Chabi J, Chandre F, Akogbeto M, Hougard JM, Carnevale P, Mas-Coma S: Efficacy of an insecticide paint against malaria vectors and nuisance in West Africa. Part II: Field evaluations. Malar J 2010.

21. Amelotti I, Catalá SS, Gorla DE: Experimental evaluation of insecticidal paints against Triatoma infestans (Hemiptera: Reduviidae), under natural climatic conditions. Parasites \& Vectors 2009, 2:30-36.

22. Rozendaal JA: Vector control methods for use by individuals and communities Geneva: World Health Organization; 1997.

23. Oliveira Filho AM: Use of new tools for controlling triatomines in different entomologic situations in the American continent. Rev Soc Bras Méd Trop 1996, 30:41-46.

24. Itoh $T$, Kawada $H$, Abe A, Eshita $Y$, Rongsriyam $Y$, Igarashi A: Utilization of bloodfed females of Aedes aegypti as a vehicle for the transfer of the insect growth regulator pyriproxyfen to larval habitats. J Am Mosa Control Assoc 1994, 10:344-347.

25. Morrison AC, Zielinski-Gutierrez E, Scott TW, Rosenberg R: Defining challenges and proposing solutions for control of the virus vector Aedes aegypti. PLoS Med 2008, 5:e68.

26. Devine GJ, Zamora Perea E, Killeen GF, Stancil JD, Clark SJ, Morrison AC: Using adult mosquitoes to transfer insecticides to Aedes aegypti larval habitats. Proc Natl Acad Sci USA 2009, 106:11530-11534.

27. Dell Chism B, Apperson CS: Horizontal transfer of the insect growth regulator pyriproxyfen to larval microcosms by gravid Aedes albopictus and Ochlerotatus triseriatus mosquitoes in the laboratory. Med Vet Entomol 2003, 17:211-220.

28. Sihunincha M, Zamora-Perea E, Orellana-Rios W, Stancil JD, LopezSifuentes V, Vidal-Ortiz C, Devine GJ: Potential use of pyriproxyfen for control of Aedes aegypti (Diptera: Culicidae) in Iquitos, Peru. J Med Entomol 2005, 42:620-630.

29. Aiku $\mathrm{AO}$, Yates $\mathrm{A}$, Rowland $\mathrm{M}$ : Laboratory evaluation of pyriproxifen treated bednets on mosquito fertility and fecundity. A preliminary study. West Afr J Med 2006, 25:22-26.

30. Devine GJ, Killeen GF: The potential of a new larviciding method for the control of malaria vectors. Malar J 2010, 9:142.

doi:10.1186/1475-2875-9-340

Cite this article as: Mosqueira et al: Efficacy of an insecticide paint against insecticide-susceptible and resistant mosquitoes - Part 1:

Laboratory evaluation. Malaria Journal 2010 9:340.

\section{Submit your next manuscript to BioMed Central and take full advantage of:}

- Convenient online submission

- Thorough peer review

- No space constraints or color figure charges

- Immediate publication on acceptance

- Inclusion in PubMed, CAS, Scopus and Google Scholar

- Research which is freely available for redistribution

Submit your manuscript at www.biomedcentral.com/submit
Biomed Central 